compliance in a more patient-centred direction - an aim of compliance therapy.

There are several shortcomings to the study. First, training was not randomly allocated. Second, we have not as yet evaluated whether the changes observed in selfrated questionnaire responses translate into genuine changes in behaviour. More sophisticated training would be required with, for example, videotaped interactions with patients (or actors) before and after training. Furthermore, we cannot say whether the attitude changes are enduring. Even if it was possible to confirm changes in skills in our trainees, we do not know whether these would be sufficient to improve the clinical outcome of patients - as demonstrated in the original compliance therapy trial (Kemp et al, 1996, 1998). Replications of that study are eagerly awaited.

Finally, we are unable to be sure that the teaching of our trainees generalises to those employed in other NHS trusts - which do not have close links to the Institute of Psychiatry. However, the 'baseline' data on attitudes and beliefs recorded on the comparison group should facilitate direct comparison with other centres.

We conclude that a 2-day compliance therapy training workshop is a successful means of broadening trainees' attitudes and producing greater awareness of patients' needs. It leads them to feel more confident - at least in the short term - in their ability to deal with the challenges posed by non-adherence to treatment in people with SMI. The efficacy of similar additional training given to general practitioners (Gask et al, 1987) and psychiatric nurses (Gournay \& Birley, 1998) is well established although it has seldom been evaluated in psychiatrists. Informal feedback from participants has suggested that the training is best done when an individual has had some experience in grappling with the problems of compliance. This means that it would be most suitable for psychiatric trainees following their Part I MRCPsych examination

\section{Acknowledgements}

The study was supported by funds for research \& development through the Bethlem and Maudsley (later South London and Maudsley) NHS Trust. We are especially grateful to Stuart Hannel of Hestia Training, who was cofacilitator/designer of the training.

\section{References}

CRAMER, J. A. \& ROSENHECK, R. (1998) Compliance with medication regimens for mental and physical disorders. Psychiatric Services, 49, 196-201.

FENTON,W. S., BLYLER, C. R. \& HEINSSEN, R. K. (1997) Determinants of medication compliance in

schizophrenia: empirical and clinical findings. Schizophrenia Bulletin, 23, 637-651.

GASK, L., MCGRATH, G., GOLDBERG D., et al (1987) Improving the psychiatric skills of established general practitioners: evaluation of group teaching. Medical Education, 21, 362-368.

GOURNAY, K. \& BIRLEY, J. (1998) Thorn: a new approach to mental health nursing. Nursing Times, $9 \mathbf{4}$, $54-55$.

KEMP, R. \& DAVID, A. (1997) Insight and compliance. In: Treatment Compliance and the Treatment Alliance in Serious Mental Illness (ed. B. Blackwell), pp. 61-84. The Netherlands: Harwood Academic Publishers.

- HAYWARD, P., APPLEWHAITE, G. et al (1996) Compliance therapy in psychotic patients: randomised controlled trial. BMJ, 312, 345-349.

- \& DAVID, A. (1997) Compliance Therapy Manual. Macclesfield: Gardiner-Caldwell.

-, KIROV, G., EVERITT, B., et al (1998) Randomised controlled trial of compliance therapy. 18 month followup. British Journal of Psychiatry, 172, 413-419.

KINGDON, D. G. \& TURKINGTON, D. (1994) Cognitive-BehaviouralTherapy

HAYNES, R. B MONTAGUE, P. OLIVER , of Schizophrenia. NewYork: Guilford $T$., et al (2000) Interventions for helping Press. patients to follow prescriptions for

medications (Cochrane Review). In: The ROLLNICK, S., KINNERSLEY, P. \& STOTT, N. (1993) Methods of helping patients with behaviour change. BMJ, 307, 188-190

Simon Surguladze Research Psychiatrist, Institute of Psychiatry, PhilipTimms Senior Lecturer in Community Psychiatry, Guy's, King's \& StThomas' School of Medicine (GKT), ${ }^{*}$ Anthony S. David Professor of Cognitive Neuropsychiatry, GKT School of Medicine \& Institute of Psychiatry, London SE5 8AF, UK original papers

Psychiatric Bulletin (2002), 26, 15-18

GRAEME LAMB, ANITA ANFIELD AND ANNE SHEERAN

\title{
Access to a child mental health service
}

\section{A comparison of Bangladeshi and non-Bangladeshi families}

\section{AIMS AND METHOD}

This was a retrospective case note analysis of all referrals to an innerLondon child and family consultation service aiming to examine any changes in patterns of referral and attendance of Bangladeshi and indigenous families over the previous 10-year period.

\author{
RESULTS \\ Bangladeshi referrals increased over \\ the period but remained under- \\ represented compared to indigenous \\ families. They were less likely to \\ attend an initial appointment, but \\ once engaged with the service drop- \\ out rates were unaffected by \\ ethnicity.
}

CLINICAL IMPLICATIONS

Improved communication between the department, families and referrers may help to increase understanding of the function of the department and lead to more equitable uptake of services in the future.
In 1987 Stern et al (1990) examined Asian and non-Asian referrals to the department of child psychiatry at the
London Hospital. Bangladeshi referrals were found to be underrepresented with respect to the local population. 
Table 1. Referral information according to ethnicity

original

papers

Non-
Bangladeshi Bangladeshi Total $n=128(\%) \quad n=316(\%) \quad n=444 \quad P$

\begin{tabular}{lcccc} 
Referral source & & & & \\
General practitioner & $19(14.8)$ & $72(22.8)$ & 91 & - \\
Self & $3(2.3)$ & $33(10.4)$ & 36 & * \\
Social services & $8(6.3)$ & $34(10.4)$ & 41 & - \\
School & $39(30.5)$ & $51(16.1)$ & 90 & ** \\
Hospital & $24(18.8)$ & $89(28.2)$ & 113 & - \\
Health visitor & $14(10.9)$ & $9(2.8)$ & 23 & ** \\
Child development & $11(8.6)$ & $6(1.9)$ & 17 & * \\
teams & & & & \\
Other & $10(7.8)$ & $23(7.2)$ & 33 & - \\
Referred problem & & & & \\
Behaviour & $51(28.2)$ & $90(21.8)$ & 141 & - \\
ADHD & $6(3.3)$ & $14(3.4)$ & 20 & - \\
Emotional & $39(21.5)$ & $99(24.0)$ & 138 & - \\
Soiling/wetting & $9(5.0)$ & $23(5.6)$ & 32 & - \\
DSH & $11(6.1)$ & $28(6.8)$ & 39 & - \\
Paediatric support & $8(4.4)$ & $26(6.3)$ & 34 & - \\
Psychiatric assess- & $9(5.0)$ & $44(10.7)$ & 53 & * \\
$\quad$ ment & & & & \\
Marital problem & $5(2.8)$ & $21(5.1)$ & 26 & - \\
Development delay & $17(9.4)$ & $16(3.9)$ & 33 & * \\
Abuse & $1(0.5)$ & $14(3.4)$ & 15 & * \\
Psychosis & $1(0.5)$ & $1(0.2)$ & 2 & - \\
Other & $24(13.3)$ & $36(8.7)$ & 60 & - \\
\hline & & & &
\end{tabular}

$* * P<0.001 * P<0.05$

$A D H D$, attention-deficit hyperactivity disorder; DSH, deliberate self-harm.

While 33\% of school-aged children in Tower Hamlets in 1987 were Bangladeshi, they accounted for only $12 \%$ of referrals to the service. Ten years later, the proportion of school-aged children in Tower Hamlets of Bangladeshi ethnicity had increased from 33\% to 52\% (Education Strategy Group, 1997). However, we hypothesised that Bangladeshi children and families remained underrepresented within the clinic population and that those who were referred, were less likely to remain engaged in treatment.

This study aims to examine and report upon any changes in patterns of referral and attendance over the intervening 10 year period.

\section{Method}

This study was a retrospective case note analysis of all referrals to the Child and Family Consultation Service at the Royal London Hospital during 1997. Data were collected by the three authors in a standardised way, recording the following demographic details: age, gender, ethnicity, postcode, referral source, presenting problem and 'administrative outcome'. The final category was divided into non-attenders, early drop-outs (attended once only), late drop-outs (attended more than once but treatment unilaterally terminated by family), agreed termination and treatment ongoing (Cottrell, et al 1998).

Data were analysed using $\chi^{2}$. Fisher's exact probability was used where sample size was small.

\section{Results}

The results are summarised in Table 1. Of the 444 referred children, 128 (28.8\%) were Bangladeshi and 316 (71.2\%) were non-Bangladeshi. Two hundred and forty-three (54.7\%) were male, 201 (45.3\%) were female. There were no statistically significant differences between the two ethnic groups in either gender or age distribution.

Of the referred children, $64(14.4 \%)$ lived outside Tower Hamlets. Of these, only 2 (3\%) children were Bangladeshi. Excluding these 64 children, Bangladeshi children accounted for $33.2 \%$ of Tower Hamlets' referrals.

Referral source was divided into eight categories (Table 1). Analyses of each referral source showed that significantly fewer Bangladeshi families referred themselves to the service, while significantly more Bangladeshi children and families were referred to the service by schools, health visitors and the child development team (CDT). The latter two sources showed a reversal in the expected trend by referring more Bangladeshi than non-Bangladeshi cases.

Referrals to the service were categorised at the point of referral into one of 39 'presenting problems'. These were contracted into 12 problems for this study (Table 1). The ethnicity differences in referral rates for psychiatric assessments were accounted for by extracontractural referrals and for development delay by CDT referrals.

Of the 44 referred cases, 407 were offered an initial appointment. Of these, 293 families (69.5\%) attended their first appointment, 25 (6.1\%) declined an appointment and 99 (24.3\%) did not attend. Of these, 61 families were offered another appointment, of whom 34 attended. The total attrition rate was 139/382 (36.4\%), while agreed discharges/ongoing treatment accounted for $239 / 382$ (62.6\%).

The 407 cases offered an initial appointment were analysed for ethnicity, revealing significant differences in patterns of response. In the Bangladeshi sample 9 (7.7\%) declined the appointment, $71(60.1 \%)$ attended and 37 (31.6\%) did not attend, while in the non-Bangladeshi group 16 (5.5\%) declined the appointment, 212 (73.1\%) attended and $62(21.4 \%)$ did not attend $(P<0.05)$. There were no differences between the ethnic groups in levels of 'early' or 'late' drop-out.

Referral source did have some influence on subsequent attendance rates at a first appointment. While 81/ $101(80.2 \%)$ children referred by the hospital were seen at a first appointment, presumably mostly as in-patients, only eight out of $19(42.1 \%)$ of those referred by health visitors attended $(P<0.05)$. Of the 86 children referred to the service by school, 55 (62.5\%) attended their first appointment. However, when these figures are analysed for ethnicity, it can be seen that only 22 of the 
38 (57.9\%) referred Bangladeshi families attended their first appointment compared to $33 / 48$ (68.8\%) non-Bangladeshi families $(P<0.05)$. No other statistically significant differences were found.

\section{Discussion}

Over the 10-year period in question, Bangladeshi referrals increased from $12 \%$ in 1987 to $29 \%$ in 1997. Examining local referrals alone, in 1997 Bangladeshi families now made up over $33 \%$ of total cases, although still less than the expected proportion.

Possible reasons for the increase in Bangladeshi cases include attempts by the service to be more accessible and acceptable to the local population. The name was changed from the Department of Child Psychiatry to the Child \& Family Consultation Service in an effort to reduce the perceived stigma of attending the service. Hospital signs have been copied into Bengali to help guide the public. Between 1987 and 1997 various Bangladeshi professionals have been part of the child mental health team, as well as Sylheti-speaking workers to help with interpreting and cultural advice (Sylhet being the province of Bangladesh from where the majority of the local Asian population originated). In addition, the local Bangladeshi people may have become more integrated into mainstream British culture with the passage of time.

Nevertheless, despite some apparent success of the department in attracting Bangladeshi referrals, with over $50 \%$ of children in the borough, this section of the population remains underrepresented. Despite evidence of increased social disadvantage when compared to indigenous populations, some studies have suggested that Asian families may experience a lower prevalence of child psychiatric disorder requiring professional help (Butler \& Golding, 1986, Hackett et al, 1991). Alternatively, perhaps more work needs to be done to break down cultural barriers to accessing good child mental health care.

Stern et al (1990) found no differences in referral source with regard to ethnicity, whereas several differences were apparent in our study. Schools, health visitors and the CDT referred a higher proportion of Bangladeshi children than most other referrers, for which there may be a number of possible explanations. Bangladeshi families may be actively seeking referral to the child mental health service through a source familiar to them. However, the poor attendance rate for the first appointment among Bangladeshi children referred by schools suggests that this is not the case. These referrers may be correctly identifying a level of need irrespective of ethnicity or highlighting a difference in the perception of what constitutes a disorder between themselves and parents.

CDT referrals show good uptake of first appointments irrespective of ethnicity. Bangladeshi children with development delay are usually allocated a 'parent advisor' from their own culture to help their parents with the difficulties of coping with a child with disabilities and to

support the families in their dealings with professionals. This additional factor may be crucial in helping these families to understand the reasons for referral to child mental health and to support attendance.

As well as making up a smaller overall proportion of referrals than their population size would indicate, Bangladeshi families are less likely to attend their initial appointment. In any consultation where the individual has to initiate contact many factors may influence access, including previous experience, education and perception of the service (Hillier et al, 1994). These factors are likely to be amplified by cultural and religious differences in health-seeking behaviour.

When taken alongside the lower self-referral rate among the Bangladeshi population, these findings appear to suggest that many Bangladeshi families are less able or less willing to seek help from a child mental health service. Of the very few Bangladeshi families that did self-refer, all attended their first appointment.

Early and late drop-out rates showed no ethnic differences, indicating that when families did make it to their first appointment, likelihood of engaging in on-going work was unaffected by language and cultural differences.

Communication between referrer, family and our service is a crucial factor in aiding access to health services (Chan, 1998). Liaison with the local Bangladeshi community reveals a widespread lack of awareness about the role and function of a child mental health service.

Possible solutions include distributing information leaflets written in Bengali about our service within the wider community. Information for our referrers to explain the service and how to access it would help reduce the number of inappropriate referrals. Particular emphasis could be given to specific professional groups such as health visitors or teachers to help them identify appropriate families to refer and prepare them for an initial appointment. Contacting families prior to an appointment to discuss the referral and help initiate engagement might help increase attendance at a subsequent appointment (Gatrad, 2000). Ensuring an adequate mix of professionals from different ethnicities to reflect the local population has not always been easy to achieve. Recruiting trainees into the professions from the local community might help address this.

We hope that the implementation of some or all of these measures will ensure that by the end of the next decade, ethnicity is no longer a major obstacle to accessing a child mental health service.

\section{References}

BUTLER, N. \& GOLDING, J. (1986) From Birth to Five: A Study of the Health and Behaviour of Britain's 5 year olds. Oxford: Pergamon.

CHAN, M. (1998) Ethnic health matters. Annals of Tropical Paediatrics, 18, S61-S65.

COTTRELL, D., HILL, P., WALK, D., et al. (1998) Factors influencing non-attendance at child psychiatry out-patient appointments. British Journal of Psychiatry, 152, 210-204.

EDUCATION STRATEGY GROUP (1997) Education and Community Services Directorate. London: London Borough of Tower Hamlets Statistics Bulletin.

GATRAD, A. R. (2000) A completed audit to reduce hospital outpatients original

papers 
non-attendance rates. Archives of Disease in Childhood, 82, 59-61.

HACKETT, L, HACKETT, R. \& TAYLOR,

original

papers its associations in the Gujerati
HILLIER, S., LOSHAK, R., RAHMAN, S. et al (1994) An evaluation of child psychiatric services for Bangladesh parents. Journal of Mental Health, D. (1991) Psychological disturbance and 3, 327-337. and Psychiatry, 32, 851-856.

STERN, G., COTTRELL, D. \& HOLMES, J. (1990) Patterns of attendance of child

reference to Asian families. British Journal of Psychiatry, 156, 384-387. psychiatry out-patients with special

${ }^{*}$ G. Lamb Consultant Child \& Adolescent Psychiatrist, Newham Child \& Family Consultation Service, York House, 411 Barking Rd, London E13 8AL,

A. Anfield Consultant Child \& Adolescent Psychiatrist, Braintree, Essex,

A. Sheeran Clinical Psychologist, North London Forensic Service

\section{ALISON NAPIER}

\section{A national survey of old age psychiatry services in Wales}

\begin{abstract}
AIMS AND METHOD
A postal questionnaire was circulated to all consultants in old age psychiatry in Wales, examining provision of services with reference to the indicative service levels defined by the Royal College of Psychiatrists and Royal College of Physicians.
\end{abstract}

\section{RESULTS}

The response rate was $100 \%$. Levels of staffing and resources overall fell well below recommendations and varied widely between services. The average population over 65 served by a whole time consultant was 22 995; more than twice that recommended. No association was found between morale or how well population needs were perceived as being met, and the size of the population served.

\section{CLINICAL IMPLICATIONS}

Considerable investment in staff and other resources is needed for the recommendations made by the royal Colleges concerning service levels and, by implication, service quality to be met.
The population of Britain is ageing. By 2010 estimates predict that more than 2.3 million people will be over the age of 80 (Government Statistical Service, 1993). This has major implications for service needs for the elderly with mental health problems. Not only will the numbers of elderly people developing dementia or functional illness increase significantly, but those who have developed enduring mental illness when young will age also.

With the advent of devolution the examination of psychiatric services for the elderly in Wales as a discrete entity appears particularly relevant.

The increasing emphasis on clinical governance and on provision of services based on population need rather than historical precedent has led to more formal approaches to service planning being adopted.

Previous studies concerning service provision in old age psychiatry (Benbow \& Jolley 1992; Wattis 1998a,b) and the recent Audit Commission report, Forget Me Not - Mental Health Services for Older People (Audit Commission, 2000) found marked geographical differences between the services examined. The Audit Commission found that spending on services for the elderly with mental illness varied between $£ 300000$ and f2.5 million per 10000 elderly population.

The Royal Colleges of Physicians and Psychiatrists have produced guidelines for indicative service levels in the report The Care of Old People with Mental Illness: Specialist Services and Medical Training (Royal College of Psychiatrists \& Royal College of Physicians, 1998)

Defining services currently in place is an important step in planning coherently for change. Therefore, this study was designed to gather information regarding existing old age psychiatry services and to establish whether the Colleges' recommendations had been met.

\section{The study}

A total of 25 consultants were identified from information supplied by the Royal College of Psychiatrists and by telephoning each individual trust. Two posts were identified as vacant.

Consultants provided the most obvious point of contact, as most services are consultant-led. A copy of the questionnaire was sent by post to each consultant in May 1999. Those who did not respond initially were sent a further copy 6 weeks later.

The questionnaire covered the following areas:

- size of population served

- staffing

- provision of NHS acute, respite and long-term beds and day hospital places

- subjective opinions concerning morale and how population needs were being met

- opportunities for general comments by respondents.

The aims of the study were to examine the existing provision of old age psychiatry services in Wales and compare this with the indicative service levels published by the Royal College of Psychiatrists and Royal College of Physicians (1998), and to gather consultants' subjective opinions of their services and look for any association with the size of the population served. 